\title{
Parametric Binding Images of the TSPO Ligand ${ }^{18}$ F-DPA-714
}

Sandeep S.V. Golla ${ }^{1}$, Ronald Boellaard ${ }^{1}$, Vesa Oikonen ${ }^{2}$, Anja Hoffmann ${ }^{3}$, Bart N.M. van Berckel ${ }^{1}$, Albert D. Windhorst ${ }^{1}$, Jere Virta ${ }^{2}$, Erik T. te Beek ${ }^{4}$, Geert Jan Groeneveld ${ }^{4}$, Merja Haaparanta-Solin ${ }^{2}$, Pauliina Luoto ${ }^{2}$, Nina Savisto ${ }^{2}$, Olof Solin ${ }^{2}$, Ray Valencia ${ }^{3}$, Andrea Thiele ${ }^{3}$, Jonas Eriksson ${ }^{1}$, Robert C. Schuit ${ }^{1}$, Adriaan A. Lammertsma ${ }^{1}$, and Juha O. Rinne ${ }^{2}$

${ }^{I}$ Department of Radiology and Nuclear Medicine, VU University Medical Center, Amsterdam, The Netherlands; ${ }^{2}$ Turku PET Centre, University of Turku and Turku University Hospital, Turku, Finland; ${ }^{3}$ Bayer HealthCare AG, Berlin, Germany; and ${ }^{4}$ Center for Human Drug Research, Leiden, The Netherlands

\begin{abstract}
${ }^{18} \mathrm{~F}$-labeled $\mathrm{N}, \mathrm{N}$-diethyl-2-(2-[4-(2-fluoroethoxy)phenyl]-5,7-dimethylpyrazolo[1,5-a]pyrimidine-3-yl)acetamide (DPA-714) is a radioligand for the 18-kDa translocator protein. The purpose of the present study was to identify the best method for generating quantitative parametric images of ${ }^{18} \mathrm{~F}-\mathrm{DPA}-714$ binding. Methods: Ninety-minute dynamic ${ }^{18} \mathrm{~F}-\mathrm{DPA}-714$ PET scans with full arterial sampling from 6 healthy subjects and 9 Alzheimer disease (AD) patients were used. Plasma-input-based Logan graphical analysis and spectral analysis were used to generate parametric volume of distribution $\left(\mathrm{V}_{T}\right)$ images. Five versions of Ichise, reference Logan, and 2 basis function implementations (receptor parametric mapping and simplified reference tissue model 2 [SRTM2]) of SRTM, all using gray matter cerebellum as the reference region, were applied to generate nondisplaceable binding potential $\left(\mathrm{BP}_{\mathrm{ND}}\right)$ images. Results: Plasma-input Logan analysis $\left(r^{2}=0.99\right.$; slope, 0.88) and spectral analysis $\left(r^{2}=0.99\right.$, slope, 0.93) generated estimates of $V_{T}$ that correlated well with values obtained using nonlinear regression. $\mathrm{BP}_{\mathrm{ND}}$ values generated using SRTM2 $\left(r^{2}=0.83\right.$; slope, 0.95) and reference Logan analysis $\left(r^{2}=\right.$ 0.88 ; slope, 1.01) correlated well with nonlinear regression-based estimates. Conclusion: Both Logan analysis and spectral analysis can be used to obtain quantitatively accurate $V_{T}$ images of ${ }^{18} \mathrm{~F}-\mathrm{DPA}$ 714. In addition, SRTM2 and reference Logan analysis can provide accurate $\mathrm{BP}_{\mathrm{ND}}$ images. These parametric images could be used for voxel-based comparisons.
\end{abstract}

Key Words: ${ }^{18} \mathrm{~F}-\mathrm{DPA}-714$; PET; parametric images; TSPO

J Nucl Med 2016; 57:1543-1547

DOI: 10.2967/jnumed.116.173013

I ncreased activation of microglial cells can be detected early after brain injury (l). Although microglial activation has been linked to normal aging, it is primarily associated with neuroinflammation caused by a variety of diseases such as multiple sclerosis, multiplesystem atrophy, and Alzheimer disease (AD) (2). An increase in activated microglia results in higher expression of the $18-\mathrm{kD}$ translocator protein (TSPO) (3). Consequently, TSPO has been a target of interest for developing diagnostic PET tracers.

Received Jan. 25, 2016; revision accepted Apr. 25, 2016.

For correspondence or reprints contact: Sandeep S.V. Golla, Department of Radiology and Nuclear Medicine, VU University Medical Center, P.O. Box 7057, 1007MB Amsterdam, The Netherlands.

E-mail: s.golla@vumc.nl

Published online Jun. 3, 2016.

COPYRIGHT (c) 2016 by the Society of Nuclear Medicine and Molecular Imaging, Inc.
${ }^{18}$ F-labeled $N, N$-diethyl-2-(2-[4-(2-fluoroethoxy)phenyl]-5,7dimethylpyrazolo[1,5- $\alpha$ ]pyrimidine-3-yl)acetamide (DPA-714) is a PET ligand with high specificity for TSPO. Early studies showed that ${ }^{18} \mathrm{~F}$-DPA-714 had better bioavailability (4), lower nonspecific binding, and higher nondisplaceable binding potential $\left(\mathrm{BP}_{\mathrm{ND}}\right)$ than ${ }^{11} \mathrm{C}$-DPA-713 (5). It is considered to be superior to ${ }^{11} \mathrm{C}$ PK11195 (6-9) in specificity, and hence, it could be a potential tracer for assessing the early stages of $\mathrm{AD}$.

A recent study (10) quantified ${ }^{18}$ F-DPA-714 binding using nonlinear regression (NLR) of regional time-activity curves and a metabolite-corrected plasma input function. ${ }^{18} \mathrm{~F}-\mathrm{DPA}-714$ kinetics were described best by a reversible 2-tissue-compartment model with blood volume fraction parameter. In the same study, data from $\mathrm{AD}$ patients and healthy subjects were compared with each other, but ${ }^{18} \mathrm{~F}-\mathrm{DPA}-714$ did not allow for identifying individual $\mathrm{AD}$ patients. This comparison, however, was based on predefined regions of interest of various brain structures, and possible differences in parts of these regions may have gone unnoticed because of dilution with nondifferent parts in the same regions.

The main purpose of this study was to identify the most suitable method for parametric quantification of ${ }^{18} \mathrm{~F}-\mathrm{DPA}-714$ binding. A secondary aim was to assess whether these parametric images can be used to compare healthy subjects and $\mathrm{AD}$ patients at the voxel level.

\section{MATERIALS AND METHODS}

\section{Subjects}

The materials of this study were the same as for a previous study in which the optimal tracer kinetic model for ${ }^{18} \mathrm{~F}-\mathrm{DPA}-714$ was identified (10). In short, 9 probable-AD patients (mean age $\pm \mathrm{SD}, 73.7 \pm 8.4 \mathrm{y}$; mini-mental state examination, $24.6 \pm 2.8$; disease duration, $2.5 \pm$ $1.7 \mathrm{y}$ ) and 6 healthy subjects (mean age, $64.5 \pm 5.5 \mathrm{y}$; mini-mental state examination, $28.8 \pm 0.8$ ) were included. $\mathrm{AD}$ patients were considered only if they fulfilled the criteria of the National Institute of Neurologic and Communicative Disorders and Stroke and the Alzheimer Disease and Related Disorders Association and the fourth edition of Diagnostic and Statistical Manual of Mental Disorders. The study was approved by the Finnish Medicines Agency, The Netherlands Central Committee on Research Involving Human Subjects, the local Ethics Committees of the Southwest Hospital District of Finland, and the VU University Medical Center. It was conducted in line with the Helsinki Declaration and was registered at www.ClinicalTrials.gov (NCT01009359). All subjects gave written informed consent for participation in the study.

\section{Scanning Protocol}

Structural T1-weighted MR images were acquired for all subjects on an Intera 1.5-T scanner (Philips). Dynamic PET emission scans (90 min) were acquired using an ECAT EXACT HR + scanner (CTI/ Siemens) after administration of $250 \pm 10 \mathrm{MBq}$ of ${ }^{18} \mathrm{~F}-\mathrm{DPA}-714$. 
Before this emission scan, a transmission scan was acquired for attenuation correction purposes. Dynamic scans were reconstructed into a single dynamic dataset of 33 frames $(6 \times 5,3 \times 10,3 \times 20,4 \times 60,6 \times$ 180 , and $11 \times 360 \mathrm{~s}$ ) using 2-dimensional filtered backprojection with Fourier rebinning, a Hanning filter (cutoff, 0.5), a matrix size of $256 \times$ $256 \times 47$, a field of view of $15.7 \mathrm{~cm}$, and a final voxel size of $1.17 \times$ $1.17 \times 3.27 \mathrm{~mm}$. All appropriate corrections for dead time, attenuation, scatter, and randoms were applied during reconstruction. In addition, the metabolite-corrected parent plasma input function was measured using an automated arterial blood sampling system (ABSS; Allogg), together with manual blood samples collected at 6 different times (5, $10,20,30,45$, and $60 \mathrm{~min}$ after injection). These manual samples were used to estimate plasma-to-whole-blood concentration ratios and labeled metabolite fractions.

\section{Data Analysis}

For each subject, MRI data were coregistered to the summed ${ }^{18} \mathrm{~F}$ DPA-714 image (0.3-24 min) using VINCI software (11). Regional time-activity curves were extracted using PVELab software (12), in which the Hammers template (13) was projected onto the coregistered MRI scan and subsequently applied to the dynamic ${ }^{18} \mathrm{~F}-\mathrm{DPA}-714$ scan. Regional kinetic parameters $\left(\mathrm{BP}_{\mathrm{ND}}\right.$, distribution volume $\left[\mathrm{V}_{\mathrm{T}}\right]$, and the rate constant from blood to tissue $K_{1}$ ) were obtained using NLR and the reversible 2-tissue-compartment model with blood volume fraction parameter as described previously (10). Results from that previous study suggested that cerebellum might be used as a reference region to assess distribution volume ratio (DVR). DVR is the ratio of regional to reference $\mathrm{V}_{\mathrm{T}}$. Cerebellum was also used as the reference region to obtain $\mathrm{BP}_{\mathrm{ND}}$ using the simplified reference tissue model (SRTM) (14). Kinetic parameters were used to assess the performance of various parametric methods.

Parametric Methods. Parametric $\mathrm{V}_{\mathrm{T}}$ images were generated using plasma input-based Logan analysis (15) and spectral analysis (16). Regional $\mathrm{V}_{\mathrm{T}}$ values were extracted from these parametric images using the Hammers template (13). Values obtained for all regions from the Hammers template were then compared with corresponding (same region) $\mathrm{V}_{\mathrm{T}}$ values obtained using NLR.

For NLR, cerebellum was used as the reference tissue to generate parametric $\mathrm{BP}_{\mathrm{ND}}$ images. Six types of reference input-based linearization techniques-that is, 5 versions of the multilinear reference tissue models (MRTM0, MRTM1, MRTM2, MRTM3, and MRTM4) (17-19) and reference Logan analysis (20)-were used to generate parametric $\mathrm{BP}_{\mathrm{ND}}$ (DVR-1 using reference Logan analysis) images.

Finally, again using cerebellum as the reference region, $\mathrm{BP}_{\mathrm{ND}}$ images were generated using 2 basis function implementations of SRTM, that is, receptor parametric mapping (RPM) (21) without and with fixing of the efflux rate constant of the reference region. In the latter approach (SRTM2), the efflux rate constant of the reference region is first estimated for each voxel using RPM and subsequently fixed to its median value in a second run, as described by $\mathrm{Wu}$ and Carson (22). Regional $\mathrm{BP}_{\mathrm{ND}}$ values from the parametric images were compared with NLR-derived DVR-1 and SRTM $\mathrm{BP}_{\mathrm{ND}}$, respectively, to evaluate the accuracy of each implementation.

Table 1 lists, where appropriate, time intervals and range of basis functions for all parametric implementations investigated. These settings were derived empirically, such as by using the linear part of the Logan plot (15-20) or by calibrating the range of basis functions based on regional NLR microparameter values (21). In the case of Logan and reference Logan analyses, different start and end times were evaluated and compared with corresponding NLR estimates to assess the optimal time points. Similarly, different ranges and numbers of basis functions were explored and regional values were compared with corresponding NLR values to identify optimal settings for each implementation. Parametric images were obtained using software developed in house (PPET) (23).
Statistical Parametric Mapping (SPM). In a previous study (10), no significant differences in ${ }^{18} \mathrm{~F}-\mathrm{DPA}-714$ binding at a regional level were found between AD patients and healthy subjects. Parametric images make it possible to investigate differences in binding at a voxel level. Therefore, the most appropriate parametric images, together with SPM8 (http://www.fil.ion.ucl.ac.uk/spm/software/spm8/), were used to perform a preliminary analysis for assessing whether differences in ${ }^{18} \mathrm{~F}$-DPA-714 binding between subject groups could be detected. The main aim of this analysis was to assess whether these parametric methods can be used for a voxelwise analysis. Clinical interpretation is beyond the scope of the present study and will require larger patient samples that are homogeneous with respect to genotype. Each subject's T1-weighted MRI scan was normalized to Montreal Neurologic Institute space as defined by the SPM template. Next, the resulting normalization parameters were applied to individual $\mathrm{V}_{\mathrm{T}}$ and $\mathrm{BP}_{\mathrm{ND}}$ images. SPM analyses were performed using the 2-sample $t$ test $(P<$ 0.05 , cluster size $>25$ ). In addition, SPM analyses were used to assess the correlation of parametric $\mathrm{V}_{\mathrm{T}}$ and $\mathrm{BP}_{\mathrm{ND}}$ with age, mini-mental state examination, and disease duration. Parametric images were also obtained from the datasets that were corrected for partial-volume effect (PVE) using iterative deconvolution $(8,24)$. Additional SPM analyses were performed using these PVE-corrected parametric images.

\section{RESULTS}

\section{Parametric Images}

Figure 1 shows examples of various parametric images generated using both plasma input-based and reference tissue-based parametric methods. In addition, $\mathrm{R}_{1}$ (relative delivery) images obtained using RPM and SRTM2 are shown, as well as $\mathrm{V}_{\mathrm{T}}$ images obtained using spectral analysis and Logan plot analysis. Interestingly, none of the MRTM implementations provided parametric images with acceptable visual image quality.

Regional parametric $\mathrm{V}_{\mathrm{T}}$ values derived using plasma input Logan analysis and spectral analysis correlated well $\left(r^{2}=0.99\right.$ and 0.99 , respectively) with those obtained using plasma input NLR (Fig. 2). $\mathrm{BP}_{\mathrm{ND}}$ derived from RPM, SRTM2, and reference Logan analysis plotted against those obtained from reference tissue NLR $\left(\mathrm{BP}_{\mathrm{ND}}\right)$ are shown in Figure 3. $\mathrm{BP}_{\mathrm{ND}}$ data generated using RPM $\left(r^{2}=\right.$ $0.84)$, SRTM2 $\left(r^{2}=0.83\right)$, and reference Logan analysis $\left(r^{2}=\right.$ 0.88 ) correlated well with NLR estimates based on SRTM. Table 2 provides correlations, slopes, and intercepts obtained for all the parametric implementations against their corresponding NLR

\section{TABLE 1}

Settings Used for Various Parametric Implementations

\begin{tabular}{lrcc}
\hline Parametric method & $\begin{array}{c}\text { Interval } \\
(\mathrm{min})\end{array}$ & $\begin{array}{c}\text { Basis function } \\
\text { range }\left(\mathrm{min}^{-1}\right)\end{array}$ & $\begin{array}{c}\text { Number of } \\
\text { basis functions }\end{array}$ \\
\hline Logan & $30-90$ & - & - \\
MRTM0 & $10-90$ & - & - \\
MRTM1 & $10-90$ & - & - \\
MRTM2 & $10-90$ & - & - \\
MRTM3 & $10-90$ & - & - \\
MRTM4 & $10-90$ & - & - \\
Spectral & $0-90$ & $0.0005-0.0583$ & 40 \\
Reference Logan & $30-90$ & - & - \\
RPM & $0-90$ & $0.03-0.1$ & 40 \\
SRTM2 & $0-90$ & $0.03-0.1$ & 40 \\
\hline
\end{tabular}




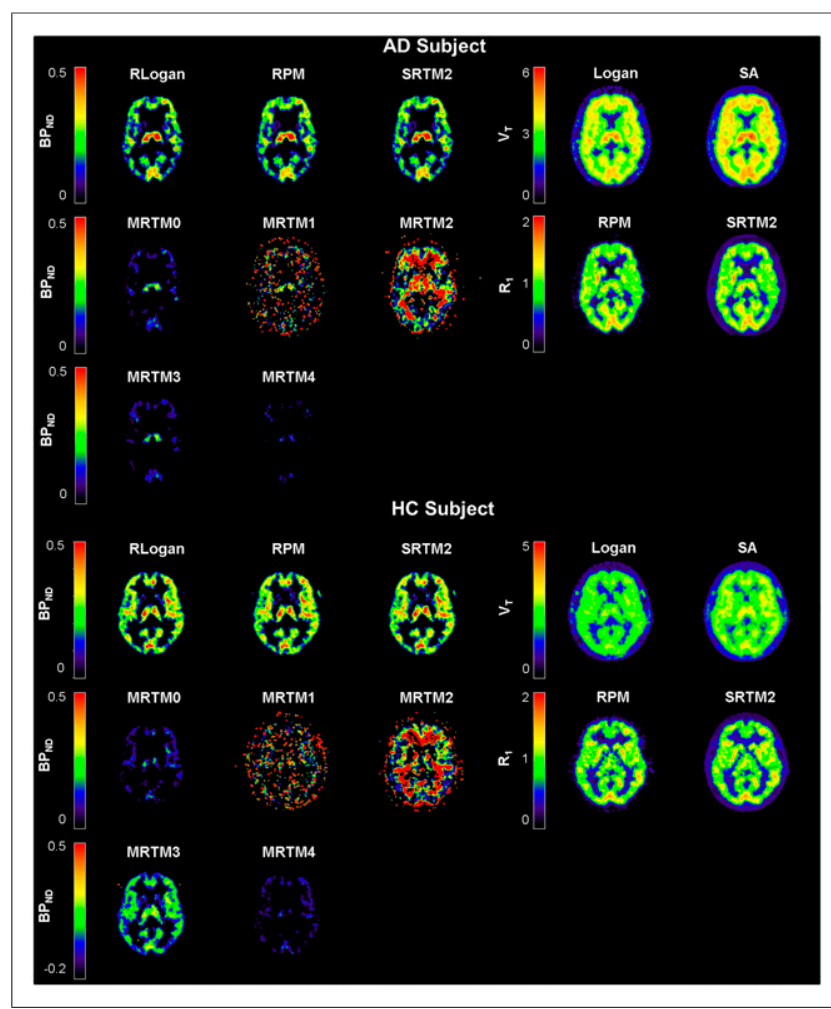

FIGURE 1. Parametric ${ }^{18} \mathrm{~F}-\mathrm{DPA}-714 \mathrm{BP}_{\mathrm{ND}}, \mathrm{V}_{\mathrm{T}}$, and $\mathrm{R}_{1}$ images, generated using reference Logan (RLogan) analysis, RPM, SRTM2, Logan analysis, spectral analysis (SA), and 5 versions of MRTM for typical $A D$ and healthy control $(H C)$ subjects.

counterparts. Regional $\mathrm{BP}_{\mathrm{ND}}$ derived from reference Logan analysis $\left(r^{2}=0.95\right), \operatorname{RPM}\left(r^{2}=0.80\right)$, and SRTM2 $\left(r^{2}=0.80\right)$ also correlated well with $\mathrm{BP}_{\mathrm{ND}}$ (calculated from DVR-1) obtained from plasma input NLR.

\section{SPM}

Based on the good quantitative results of $\mathrm{V}_{\mathrm{T}}$ obtained using Logan and spectral analysis, and those of $\mathrm{BP}_{\mathrm{ND}}$ obtained using SRTM2 and reference Logan analysis, parametric images of the methods were used for further analysis. Using SPM, significant differences were seen between subject groups for $\mathrm{BP}_{\mathrm{ND}}$ images in parts of the frontal and medial temporal lobes (Supplemental Fig. 1; available at http:// jnm.snmjournals.org). $R_{1}$ images also showed significant differences between the subject groups but with smaller clusters. No clusters were found that showed a correlation with age, mini-mental state examination, or disease duration (within the $\mathrm{AD}$ patient group) in any of the parametric images. Supplemental Figure 2 illustrates the impact of PVE correction on observed differences.

\section{DISCUSSION}

After the previous study in which the optimal tracer kinetic model was identified (10), the focus of the present study was to assess various parametric methods for quantitative analysis of ${ }^{18} \mathrm{~F}-\mathrm{DPA}-714$ PET studies. In the case of plasma input, both Logan analysis and spectral analysis provided $\mathrm{V}_{\mathrm{T}}$ estimates that correlated well with those obtained from full kinetic analyses (NLR). Similarly, both reference Logan analysis and SRTM2, using cerebellum as the reference region, provided reliable estimates of $\mathrm{BP}_{\mathrm{ND}}$ compared with those seen with SRTM. Finally, applying SPM to the parametric images mentioned above provided small but significant differences between healthy controls and $\mathrm{AD}$ patients in parts of the frontal and medial temporal lobes, which went unnoticed in the previous analysis using predefined regions of interest. However, the observed small differences seem to decrease further after PVC. Therefore, care should be taken in interpreting the observed differences, as this will require larger sample sizes that are homogeneous with respect to genotype.

Figure 2 and Table 2 illustrate that the parametric images generated by the Logan plot slightly underestimate $V_{T}$ compared with full kinetic analysis. This underestimation has been described previously and was attributed to noise-induced negative bias (25). In addition, the Logan linearization in our implementation does not take into account the fractional blood volume, which may also result in a negative bias. Unlike Logan analysis, spectral analysis incorporates a blood volume fraction parameter, which is likely to explain the better agreement with $\mathrm{V}_{\mathrm{T}}$ estimates derived from full kinetic analysis (slope closer to 1 in Table 2). Outliers in Figures 2 and 3 are neither from the same subject nor from the same region. These outliers result from regions that were either small or had a lower activity concentration, resulting in higher noise levels.

For the reference tissue methods, both
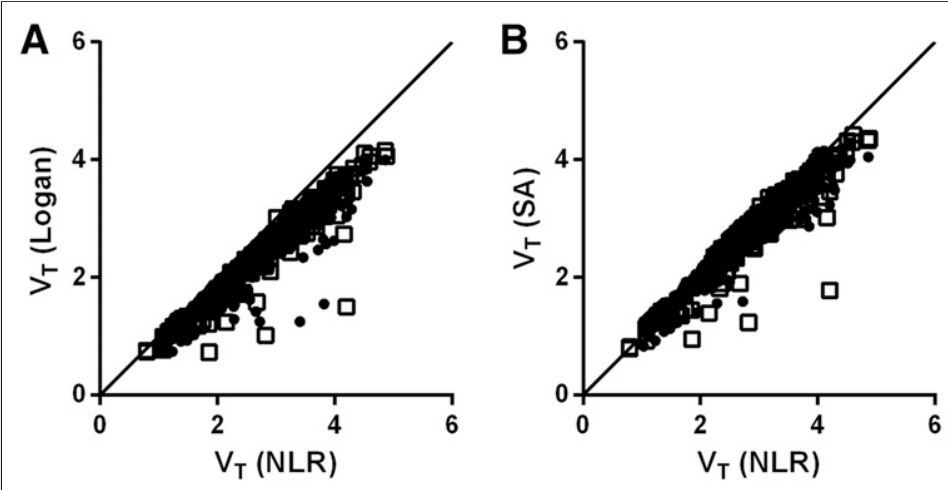

- $A D$

口 $\mathrm{HC}$

- LOI

FIGURE 2. Relationship between regional parametric values of $V_{T}$ obtained using Logan analysis (A), spectral analysis (SA) (B), and corresponding values obtained using NLR of region-ofinterest data. Using Logan linear regression, confidence intervals of $0.83-0.88$ for healthy controls (HCs) and 0.81 to 0.85 for $A D$ patients were observed. For SA, confidence intervals were $0.87-$ 0.92 and $0.8-0.90$ for $\mathrm{HCs}$ and $\mathrm{AD}$ patients, respectively. $\mathrm{LOI}=$ line of identity. reference Logan analysis and SRTM2 showed good correlations $(0.88$ and 0.83 , respectively) between $\mathrm{BP}_{\mathrm{ND}}$ and the corresponding NLR values. An important advantage of SRTM2 is that it also provides parametric images of relative delivery $\left(R_{1}\right)$. In principle, precision could be further improved using SRTM2, a refinement of RPM in which the rate of clearance from the reference region is fixed to the median value obtained from a first run using RPM (22). Hence, there was a better slope with SRTM2 than with RPM. Subsequently, $\mathrm{BP}_{\mathrm{ND}}$ derived from SRTM2 was used for SPM analysis.

Because TSPO is widely expressed in the brain, it is difficult, if not impossible, to define an ideal reference tissue devoid of binding sites. In the present study, cerebellum 


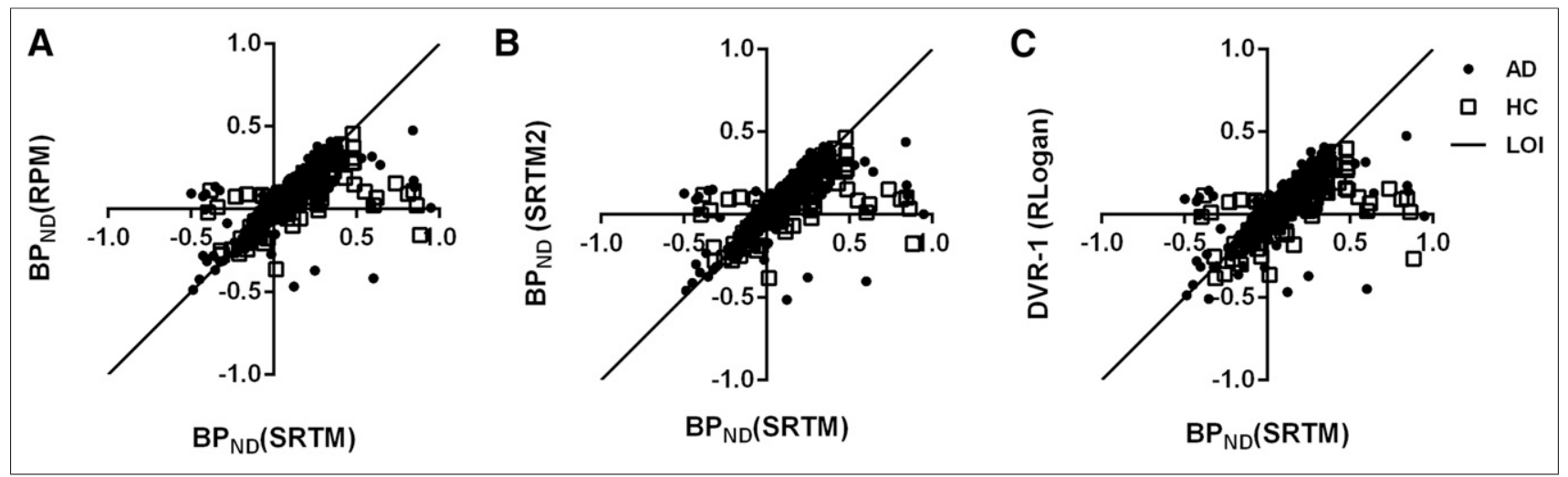

FIGURE 3. Regional parametric values of $\mathrm{BP}_{\mathrm{ND}}$ derived from RPM (A), SRTM2 (B), and reference Logan (DVR-1 [RLogan]) analysis against corresponding values obtained using SRTM-based NLR (SRTM BP $\left.{ }_{\mathrm{ND}}\right)$. LOI represents line of identity.

was used as the reference tissue. As discussed previously (10), there was no clear indication that cerebellum was not suitable as a reference region. Indeed, many studies $(26,27)$ using TSPO ligands have used cerebellum as a reference region. Nevertheless, further studies are required to validate this approach. An alternative way of obtaining a suitable reference region would be a method such as supervised cluster analysis (28). For the present study, this approach was not possible, as it requires larger datasets to predefine the necessary kinetic classes.

The significant differences between subject groups in both parametric $\mathrm{BP}_{\mathrm{ND}}$ and $\mathrm{V}_{\mathrm{T}}$ images were not seen in the previous study using predefined regions of interest (10). This discrepancy may be explained by the fact that the disease-related signal is small and comprises only part of those predefined regions of interest. Therefore, the regional comparison was diluted with many voxels in which there was no difference between $\mathrm{AD}$ patients and healthy controls. Indeed, SPM analysis revealed only small clusters, but these were in similar locations to those observed in pre-

TABLE 2

Regional Linear Regression Analyses of Parametric ${ }^{18} \mathrm{~F}-\mathrm{DPA}-714 \mathrm{~V}_{\mathrm{T}}$ and $\mathrm{BP}_{\mathrm{ND}}$ Against Corresponding NLR Methods

\begin{tabular}{lccc}
\hline Parametric method & Slope & Intercept & $R^{2}$ \\
\hline Logan $^{\star}$ & 0.88 & 0.02 & 0.99 \\
\hline MRTM0 $^{\dagger}$ & 0.51 & -0.17 & 0.24 \\
\hline MRTM1 $^{\dagger}$ & 0.45 & -0.11 & 0.15 \\
\hline MRTM2 $^{\dagger}$ & 1.34 & -0.00 & 0.24 \\
\hline MRTM3 $^{\dagger}$ & 0.81 & -0.15 & 0.20 \\
\hline MRTM4 $^{\dagger}$ & -0.93 & -0.29 & 0.02 \\
\hline Spectral $^{\star}$ & 0.93 & 0.15 & 0.99 \\
\hline Reference Logan $^{\dagger}$ & 1.01 & -0.02 & 0.88 \\
\hline RPM $^{\dagger}$ & 0.88 & 0.01 & 0.84 \\
\hline SRTM2 $^{\dagger}$ & 0.95 & 0.01 & 0.83 \\
\hline
\end{tabular}

*Using reversible 2-tissue-compartment model with additional parameter for fractional blood volume.

†Using SRTM model and with gray matter cerebellum as reference region. vious $(R)-{ }^{11} \mathrm{C}-\mathrm{PK} 11195$ studies (29) (right frontal lobe, left frontal lobe, right medial temporal lobe, and left medial temporal lobe).

Atrophy in AD subjects may have affected the observed differences in the analysis mentioned above. Because atrophy may increase PVE, there is a possibility that differences are underestimated when using datasets that are not corrected for PVE. Therefore, parametric images were also obtained using PVE-corrected datasets, with PVE correction based on iterative deconvolution. Subsequently, the SPM analysis was repeated using these PVE-corrected parametric images. Supplemental Figure 2 illustrates the impact of PVE correction on observed SPM differences. After PVE correction, clusters with significant differences became even smaller. It is likely that increased noise levels associated with PVE correction are responsible for these smaller clusters, and not atrophy in the $\mathrm{AD}$ group. Irrespective of the results, however, it can be concluded that comparisons at the voxel level are possible using parametric (BPND) images of ${ }^{18} \mathrm{~F}-\mathrm{DPA}-714$. To fully assess the impact of PVE, further studies with a larger number of subjects are necessary.

A limitation of the present study was the lack of TSPO genotype information on the subjects. Unfortunately, it will not be possible to obtain these post hoc because of the rules and regulations of the sponsor and ethical review board. Furthermore, currently it is unknown whether ${ }^{18}$ F-DPA-714 has high-affinity binding or lowaffinity binding to binding sites (30). Clearly, further studies are required in which subjects are selected for the same TSPO genotype. Another limitation might be the use of cerebellum as the reference region, as increased binding in the reference region might underestimate $\mathrm{BP}_{\mathrm{ND}}(31)$. Nevertheless, in many TSPO PET tracer studies, cerebellum has been used as a reference tissue.

\section{CONCLUSION}

Both Logan analysis and spectral analysis are suitable plasma input-based methods for generating quantitatively accurate parametric $\mathrm{V}_{\mathrm{T}}$ images. In reference tissue approaches, reference Logan analysis or SRTM2 can be used for generating parametric $\mathrm{BP}_{\mathrm{ND}}$ images.

\section{DISCLOSURE}

The costs of publication of this article were defrayed in part by the payment of page charges. Therefore, and solely to indicate this fact, this article is hereby marked "advertisement" in accordance with 18 USC section 1734. This study was sponsored by Bayer Healthcare AG, Berlin, Germany, and supported by the European 
Union's Seventh Framework Programme (FP7/2007-2013), grant HEALTH-F2-2011-278850 (INMiND). No other potential conflict of interest relevant to this article was reported.

\section{REFERENCES}

1. Kreutzberg GW. Microglia: a sensor for pathological events in the CNS. Trends Neurosci. 1996;19:312-318.

2. Venneti S, Lopresti BJ, Wiley CA. The peripheral benzodiazepine receptor (translocator protein $18 \mathrm{kDa}$ ) in microglia: from pathology to imaging. Prog Neurobiol. 2006;80:308-322.

3. Banati RB, Newcombe J, Gunn RN, et al. The peripheral benzodiazepine binding site in the brain in multiple sclerosis: quantitative in vivo imaging of microglia as a measure of disease activity. Brain. 2000;123:2321-2337.

4. Peyronneau MA, Saba W, Goutal S, et al. Metabolism and quantification of $\left[{ }^{18}\right.$ F]DPA-714, a new TSPO positron emission tomography radioligand. Drug Metab Dispos. 2013;41:122-131.

5. Chauveau F, Van CN, Dolle F, et al. Comparative evaluation of the translocator protein radioligands ${ }^{11} \mathrm{C}$-DPA-713, ${ }^{18} \mathrm{~F}$-DPA-714, and ${ }^{11} \mathrm{C}$-PK1 1195 in a rat model of acute neuroinflammation. $J$ Nucl Med. 2009;50:468-476.

6. Yokokura M, Mori N, Yagi S, et al. In vivo changes in microglial activation and amyloid deposits in brain regions with hypometabolism in Alzheimer's disease. Eur J Nucl Med Mol Imaging. 2011;38:343-351.

7. Cagnin A, Brooks DJ, Kennedy AM, et al. In-vivo measurement of activated microglia in dementia. Lancet. 2001;358:461-467.

8. Schuitemaker A, van der Doef TF, Boellaard R, et al. Microglial activation in healthy aging. Neurobiol Aging. 2012;33:1067-1072.

9. Schuitemaker A, Kropholler MA, Boellaard R, et al. Microglial activation in Alzheimer's disease: an $(R)-\left[{ }^{11} \mathrm{C}\right] \mathrm{PK} 11195$ positron emission tomography study. Neurobiol Aging. 2013;34:128-136.

10. Golla SS, Boellaard R, Oikonen V, et al. Quantification of $\left[{ }^{18} \mathrm{~F}\right] \mathrm{DPA}-714$ binding in the human brain: initial studies in healthy controls and Alzheimer's disease patients. J Cereb Blood Flow Metab. 2015;35:766-772.

11. Vollmar S, Michel C, Treffert JT, et al. HeinzelCluster: accelerated reconstruction for FORE and OSEM3D. Phys Med Biol. 2002;47:2651-2658.

12. Svarer C, Madsen K, Hasselbalch SG, et al. MR-based automatic delineation of volumes of interest in human brain PET images using probability maps. Neuroimage. 2005;24:969-979.

13. Hammers A, Allom R, Koepp MJ, et al. Three-dimensional maximum probability atlas of the human brain, with particular reference to the temporal lobe. Hum Brain Mapp. 2003;19:224-247.

14. Lammertsma AA, Hume SP. Simplified reference tissue model for PET receptor studies. Neuroimage. 1996;4:153-158.

15. Logan J, Fowler JS, Volkow ND, et al. Graphical analysis of reversible radioligand binding from time-activity measurements applied to $\left[\mathrm{N}-{ }^{11} \mathrm{C}\right.$-methyl]- (-)-cocaine PET studies in human subjects. J Cereb Blood Flow Metab. 1990;10: 740-747.

16. Cunningham VJ, Jones T. Spectral analysis of dynamic PET studies. J Cereb Blood Flow Metab. 1993;13:15-23.

17. Ichise M, Ballinger JR. From graphical analysis to multilinear regression analysis of reversible radioligand binding. J Cereb Blood Flow Metab. 1996;16: $750-752$.

18. Ichise M, Toyama H, Innis RB, Carson RE. Strategies to improve neuroreceptor parameter estimation by linear regression analysis. J Cereb Blood Flow Metab. 2002;22:1271-1281.

19. Yasuno F, Sanabria SM, Burns D, et al. PET imaging of neurokinin-1 receptors with $\left[{ }^{18} \mathrm{~F}\right] \mathrm{SPA}-\mathrm{RQ}$ in human subjects: assessment of reference tissue models and their test-retest reproducibility. Synapse. 2007;61:242-251.

20. Logan J, Fowler JS, Volkow ND, Wang GJ, Ding YS, Alexoff DL. Distribution volume ratios without blood sampling from graphical analysis of PET data. J Cereb Blood Flow Metab. 1996;16:834-840.

21. Gunn RN, Lammertsma AA, Hume SP, Cunningham VJ. Parametric imaging of ligand-receptor binding in PET using a simplified reference region model. Neuroimage. 1997;6:279-287.

22. $\mathrm{Wu} \mathrm{Y,} \mathrm{Carson} \mathrm{RE.} \mathrm{Noise} \mathrm{reduction} \mathrm{in} \mathrm{the} \mathrm{simplified} \mathrm{reference} \mathrm{tissue} \mathrm{model} \mathrm{for}$ neuroreceptor functional imaging. J Cereb Blood Flow Metab. 2002;22:1440-1452.

23. Boellaard R, Yaqub M, Lubberink M, Lammertsma A. PPET: a software tool for kinetic and parametric analyses of dynamic PET studies. Neuroimage. 2006;31: T62.

24. Teo BK, Seo Y, Bacharach SL, et al. Partial-volume correction in PET: validation of an iterative postreconstruction method with phantom and patient data. $\mathrm{J} \mathrm{Nucl}$ Med. 2007;48:802-810.

25. Slifstein M, Laruelle M. Effects of statistical noise on graphic analysis of PET neuroreceptor studies. J Nucl Med. 2000;41:2083-2088.

26. Kropholler MA, Boellaard R, Schuitemaker A, Folkersma H, van Berckel BN, Lammertsma AA. Evaluation of reference tissue models for the analysis of $\left[{ }^{11} \mathrm{C}\right](R)$-PK11195 studies. J Cereb Blood Flow Metab. 2006;26:1431-1441.

27. Lyoo CH, Ikawa M, Liow JS, et al. Cerebellum can serve as a pseudo-reference region in Alzheimer disease to detect neuroinflammation measured with PET radioligand binding to translocator protein. J Nucl Med. 2015;56:701-706.

28. Yaqub M, van Berckel BN, Schuitemaker A, et al. Optimization of supervised cluster analysis for extracting reference tissue input curves in $(R)-\left[{ }^{11} \mathrm{C}\right] \mathrm{PK} 11195$ brain PET studies. J Cereb Blood Flow Metab. 2012;32:1600-1608.

29. Schuitemaker A, van Berckel BN, Kropholler MA, et al. SPM analysis of parametric $(R)-\left[{ }^{11} \mathrm{C}\right] \mathrm{PK} 11195$ binding images: plasma input versus reference tissue parametric methods. Neuroimage. 2007;35:1473-1479.

30. Owen DR, Gunn RN, Rabiner EA, et al. Mixed-affinity binding in humans with 18-kDa translocator protein ligands. J Nucl Med. 2011;52:24-32.

31. Salinas CA, Searle GE, Gunn RN. The simplified reference tissue model: model assumption violations and their impact on binding potential. J Cereb Blood Flow Metab. 2015;35:304-311. 